\title{
Digital Media Literacy Campaign in Identifying News
}

\author{
Tandiyo Pradekso, Djoko Setyabudi and Rouli Manalu* \\ Department of Communication, Faculty of Social and Political Sciences, Universitas Diponegoro, Semarang - Indonesia
}

\begin{abstract}
This article explains the ways in which a digital media literacy campaign was conducted to help groups of adolescent to identify fake news or hoax and to prevent the further dissemination of fake news. A number of research have shown that young generation, or popularly known as millennials, is the age group of media users that has the highest tendency to read and to spread hoax or fake news. This is also tied to the fact that millennial spend more time on the Internet, and therefore have higher exposure to many various types information, including fake news. Based on the digital media campaign programs that was conducted in several public and private high schools in Semarang, Indonesia, this article will explicate the initial condition regarding the ability of high-school students in recognizing and identifying fake news before the digital media literacy campaign, and then explain how the campaign helping students to improve the ability to do so. This article will further describe the challenges faced in the typical media literacy campaign and several suggestions to overcome those challenges in future digital media literacy programs.
\end{abstract}

Keywords: Digital Media Literacy; Fake News; Hoax; Millennials; Social Campaign

\section{Introduction}

The issue of fake news, well recognized also as hoax, had broken out in Indonesia's discourse since last year. Most of the topics related to the issue were related to hatred, and manipulating religious and racial sentiments[1], particularly in the ground of political rivalry. Yet, it was not merely belong to the political domain, but also found in many field of interest, even over diverse daily trivial activities. We are potentially exposed to fake news on a daily basis, and almost by the same rate, issues and cases related to fake news fill out the mainstream media that we use (there were news related to hoax almost everyday during the second half of February 2017 in Kompas). The issue of fake news is getting worse when people could not recognized is as fabricated news and responded to it as it was an actual event, and ended up to a conflict situation in various levels and contexts.

A survey of Indonesia Telematics Society (Masyarakat Telematika Indonesia/ Mastel) conducted in February 2017 to 1.116 respondents reveals that 91.8 percent of fake news they ever receive were social and political in nature and significantly related to regional election and government in general. Most of the fake news diffused by social media $(92.4 \%)$, online messaging such as Line, Whatsapp, and Telegram $(62.8 \%)$, websites $(34.9 \%)$, television $(8.7 \%)$, print media $(5 \%)$, emails $(3,1 \%)$, and radio $(1.2 \%)[2]$. The Mastel chair further stated that to mitigate the impact of fake news, what need to be done was media literacy or digital media literacy to the people by the authority, prominent experts, as well as communities. The effort should be held with providing access to validation sources for suspected news, conducting a sustainable systematic media literacy, and enforcing effective legal action for hoax propagators.

Quoted from Cavanagh through her article that she writes on DW (2018), Hoax also occurred in environmental issues, such like climate change. Mail on Sunday published an article about the fakeness of climate change problem, and the world leaders are duped into investing billions of dollars over manipulated global warming data [6]. Below it, an article alleged that US government scientists had used misleading, unverified data in a report that greatly exaggerated global warming and rushed it to publication in time to sway the 2015 Paris climate talks. Seven months later, the IPSO ruled that the Mail on Sunday article was indeed inaccurate and misleading. The newspaper was

\footnotetext{
Corresponding author: rouli.manalu@gmail.com
} 
forced to publish the regulator's adjudication above the original article, pinpointing its flaws and inaccuracies.

Until recently, most of hoax and anti-hoax related issues were remain jargon or 'punch line' in public discourse, a comprehensive study and explanation that elaborate the characteristics of fake news was rarely found. Nevertheless, to fight and to avoid fake news people need sufficient knowledge and skill to spot and to discern the shapes and features of fake news. That is why those shapes and features, and their sources are need to be mapped, so that people could examine and screen fake news.

\section{Methodology}

The campaign was intended to compile features of fake news and identified their sources of distribution at its initial stage, and subsequently circulate the knowledge and skill via anti-hoax social campaign to the vulnerable groups. Eventually, it was expected to deliver the necessary knowhow of spotting fake news.

Simultaneously, a compilation of various techniques and measures to recognize, detect and confirm the fake news were obtained from Mastel, Kompas, and Washington Post. The compilation was then developed into an anti-hoax campaign module which consist, among other things, various indicators that can be used to spot fake news, accessible sources for checking the authenticity of news, and the legal consequences of sharing fake news.

The campaign was carried out in workshops by recruiting students of the Department of Communication as instructors and tutors. The workshop itself was conducted in phases with reference to target market (high school students) and geographic area [5] (high schools). This phasing technique is nominated with consideration to the effectiveness and efficiency of the campaign.

The programmed duration of the campaign is 3 months and held in 5 public and private high schools in Semarang. As a pilot event, SMA 9 Banyumanik was appointed to be the place of the first campaign with 68 students as participants of half day workshop. Prior to the workshop, a pretest was conducted on the initial knowledge of fake news and its features. The fact that fake news or hoax is a popular issue is reflected in the knowledge of all workshop participants who understand well the fake news or the hoax. But it is unalike when it comes to how to detect and the ability to spot fake news. Can be shown in Figure 3.

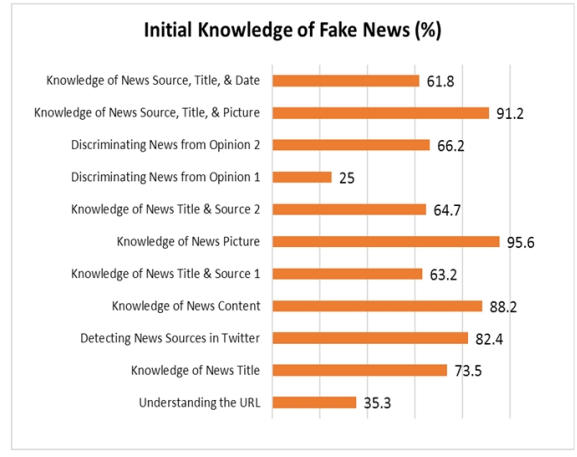

Fig. 3. Initial Knowledge of Fake News ( \% )

Workshop participants basically had the skill to recognize images from fake news, and a combination of images, titles, and sources of fake news, as well as content of fake news. On the contrary, they did not quite familiar to the characteristics of fake news from its URL. In addition, they are also not able to distinguish between facts and opinions, problems that can affect the legal consequences when they share information online. Workshop activities then continued with technical training, case study and problem solving, and group discussion.

\section{Discussion}

The anti-hoax social campaign was planned based on previous research findings on new media consumption and new media trustworthiness. This step was mainly significant in selecting the suitable target market of the campaign. The survey was conducted in the city of Semarang to 400 respondents that was chosen randomly with $95 \%$ level of confidence and $4.9 \%$ margin of error. Can be shown in Figure 1.

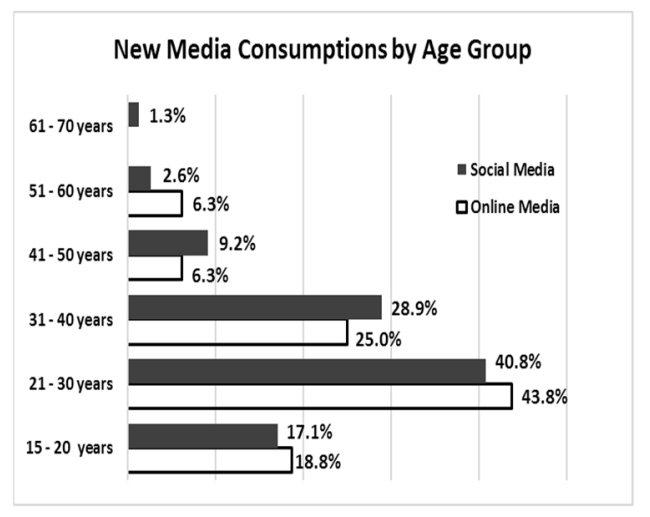

Fig. 1. New Media Consumptions by Age Group

Findings on new media consumption pattern and new media trustworthiness indicated that ages 15 to 40 years are major consumers of new media. It also revealed that social media credibility is very high among people of 15-20 years and 21-30 years old. Taking into account the priority groups concept[3] and the potential defenselessness of the target market[4] in dealing with fake news, then the chosen target group is high school students who are in the age group of 15-20 years. The choice to the age group was also based on a more 
strategic value than the older one. Can be shown in Figure 2.

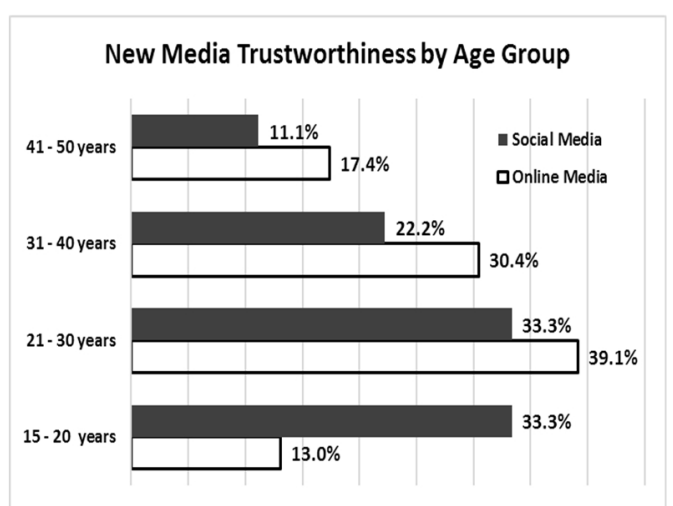

Fig. 2. New Media Trustworthiness by Age Group

\section{Conclusion}

The pilot event provided some inputs used for improving the following campaign phases in the remaining 4 high schools. Challenges arose in the first campaign were the number of participants and the size of the hall were too many and too big for a single workshop session. These increased a little bit of disarray and lack of focus among participants. On the other hand, the content of the campaign was also not fully fit to be implemented in the planned activities. So, improving campaign content and classroom based workshop would be a preference for the subsequent campaigns. The phasing technique was also confirmed to be an advantage for the campaign, that there would be ongoing improvements along the campaigns to finally produce a reliable anti-hoax campaign manual.

\section{References}

1. Kompas, Minggu, 26 Februari, 2, (2017).

2. Kompas, Kamis, 16 Februari, 13, (2017).

3. R.C. Lefebvre, Social Marketing and Social Change: Strategies and Tools for Health, WellBeing, and the Environment, (2013).

4. Kotler, Philip, N. Roberto, \& N. Lee, Social Marketing: Improving the Quality of Life ( $2^{\text {nd }}$ edition), 127 (2002).

5. Kotler, Philip, N. Roberto, \& N. Lee, "Social Marketing: Improving the Quality of Life ( $2^{\text {nd }}$ edition), 379 (2002).

6. M. Cavanagh, "Climate Change: "Fake News", Real Fallout, (2018), retrieved from https://www.dw.com/en/climate-change-fake-newsreal-fallout/a-44603523 